Chapter 3

\title{
New Insights on Neuropathic Pain Mechanisms as a Source for Novel Therapeutical Strategies
}

\author{
Sabatino Maione, Enza Palazzo, Francesca Guida, \\ Livio Luongo, Dario Siniscalco, Ida Marabese, \\ Francesco Rossi and Vito de Novellis \\ Additional information is available at the end of the chapter \\ http://dx.doi.org/10.5772/55276
}

\section{Introduction}

Injuries affecting either the peripheral or the central nervous system (PNS, CNS) leads to neuropathic pain characterized by spontaneous pain and distortion or exaggeration of pain sensation. Peripheral nerve pathologies are considered generally easier to treat compared to those affecting the CNS, however peripheral neuropathies still remain a challenge to therapeutic treatment.

Animal models such as denervation/neuroma formation [1], chronic constriction injury (CCI) by loose ligatures around the sciatic nerve [2], partial tight ligation of the sciatic nerve trunk (partial sciatic nerve ligation, PNL) [3]; tight ligature of L5 and L6 spinal nerves (spinal nerve ligation, SNL) [4]; section of one or two components of the sciatic nerve (spared nerve injury, SNI) [5]; streptozocin induced diabetic neuropathy [6] and peripheral neuropathy induced by vincristine or by anti-retroviral nucleoside analogue AIDS therapy drugs $[7,8]$ have been designed to mimic different neuropathic syndromes and reproduce in laboratory neuropathic pain main symptoms. Indeed all the mentioned neuropathic pain models show increased responses to thermal or mechanical nociceptive stimulation (hyperalgesia), hypersensitivity to innocuous tactile or cold stimuli (allodynia) which lead to withdrawal behaviour.

\section{Peripheral pathophysiology change mechanisms}

A large body of studies has been accumulated during the last two decades to characterize and clarify mechanisms at the base of neuropathic pain development and maintenance. Peripheral 
nerve injury causes axon and myelin sheath degradation associated with macrophage, neutrophil and T cell infiltrations $[9,10]$.

The release of proinflammatory cytokines (interleukins, tumor necrosis factor- $\alpha$ ) and mediators (bradykinins and prostaglandins) and growth factors (nerve growth factor) leads to peripheral sensitization and hypersensitivity to innocuous and noxious stimuli [11, 12]. Bradykinins and prostaglandins potentiates, among other things, the activity of transient receptor potential vanilloid type 1 (TRPV1) channel, highly expressed on Aס and C fibers, whose activity and expression is potentiated in neuropathic pain models [13-16]. Neuropathic pain causes also over-expression of voltage gated sodium channels and increases sodium currents leading to spontaneous discharges of $A \delta$ and $C$ fibers [17-19]. Peripheral sensitization is also associated with increased voltage gated $\mathrm{Ca}^{2+}$ channels [20, 21]. Increased intracellular $\mathrm{Ca}^{2+}$ elevates substance $\mathrm{P}(\mathrm{SP})$ and glutamate release thus exacerbating pain transmission.

\section{Spinal pathophysiology change mechanisms}

Beside the peripheral mechanisms which are responsible of the immediate damage-induced changes in pain transmission, several spinal cellular and molecular changes are involved in the development of the neuropathic pain symptoms, such as thermal and mechanical hyperalgesia and tactile allodynia. Although first being thought as a disease of purely neuronal nature, several pre-clinical studies indicate that the mechanisms at the basis of the development and maintenance of neuropathic pain involve substantial contributions from the nonneuronal cells of both the PNS and CNS [22]. After peripheral nerve injury, microglia in the normal conditions (usually defined "resting" microglia) in the spinal dorsal horn proliferate and change their phenotype to an "activated" state through a series of cellular and molecular changes.

Microglia shift their phenotype to the hypertrophic "activated" form following altered expression of several molecules including cell surface receptors, intracellular signalling molecules and diffusible factors. The activation process consists of distinct cellular functions aimed at repairing damaged neural cells and eliminating debris from the damaged area [23]. Damaged cells release chemo-attractant molecules that both increase the motility (i.e. chemokinesis) and stimulate the migration (i.e. chemotaxis) of microglia, the combination of which recruits the microglia much closer to the damaged cells [24]. It has been shown that microglia activation in the spinal cord can be promoted by sciatic nerve ligation [25], spinal nerve ligation [26], sciatic nerve inflammation [27], traumatic nerve transection [28] and autoimmune diseases such as autoimmune encephalomyelitis and neuritis (EAE, EAN) [29, 30].

Once microglia become activated, they can exert both proinflammatory or anti-inflammatory/ neuroprotective functions depending on the combination of the stimulation of several receptors and the expression of specific genes [31]. Thus, the activation of microglia following a peripheral injury can be considered as an adaptation to tissue stress and malfunction [32] that contribute to the development and subsequent maintenance of chronic pain [33,34]. 
Spinal microglia respond quickly to injury, up-regulating cell surface proteins and increasing synthesis and the release of inflammatory mediators, including cytokines and proteases that can sensitize neurons, thereby establishing positive feedback which helps to facilitate nociceptive signalling [35]. Accordingly, the inhibition of microglia targets can reduce hypersensitivity in neuropathic pain states.

The signals responsible for neuron-microglia and/or astrocyte communication are being extensively investigated since they may represent new targets for chronic pain management.

The first candidates are substances released by activated nociceptive primary afferent fibers, such as glutamate and SP, which are capable to activate microglia [36, 37]. Glutamate activates microglia by stimulating NMDA receptors [37], although other mechanisms involving metabotropic glutamate receptors (mGluRs) cannot be ruled out since it has been shown that mGluRs are expressed on microglial cells [38, 39]. SP acts mostly by activating microglia neurokinin-1 (NK1) receptors. Many mechanisms have been proposed for neuron-microglia crosstalk. Among these, the fractalkine (FKN, CX3CL1), a member of CX3C class of chemokines and its receptor CX3CR1 have been extensively investigated [39]. FKN is constitutively expressed by spinal cord and sensory neurons in the dorsal root ganglia (DRGs) [40-42], while CX3CR1 is exclusively expressed by microglia cells and, after peripheral nerve injury it is largely up-regulated in activated microglia [41]. FKN produces nociceptive behaviour by activating CX3CR1 on microglia and p38 mitogen-activated protein kinase (MAPK)-mediated pathways $[42,43]$. A pathway for the cleavage of FKN from the membrane of neurons, has been elegantly demonstrated [42]. Briefly, neuronal FKN is cleaved by Cathepsin S (CatS), a proteolitic enzyme which is synthesized and released by activated microglia. Despite the CX3CL1/CX3CR1 pathway represents a pro-nociceptive non adaptive process, seems to perform also a neuro-protective action in neurodegenerative diseases [44].

Another chemokine implicated in neuron-glia communication is the chemokine (C-C motif) ligand 2 (CCL2, MCP-1), which is de novo expressed by sensory neurons as early as a day after peripheral injury [44]. Once released, CCL2 activates microglia via interaction with CCR2 receptors, and, accordingly, mice lacking CCR2 receptors display a reduction in nerve injuryinduced tactile allodynia [45]. The action of the monocyte chemoattractant protein 1 (MCP-1) at the spinal level has also been demonstrated by the intrathecal administration of an MCP-1 neutralizing antibody, which proved able to inhibit neuropathic pain symptoms [44]. Another important candidate for neuronal-microglial cross-talk is ATP, that is produced by neurons as well as by glial cells. ATP exerts its effect on microglia by activating the purinergic ionotropic $\mathrm{P} 2 \mathrm{X} 4$ and P2X7, as well as the metabotropic P2Y6 and P2Y12, receptors which are up and/or down-regulated in several conditions [46]. The stimulation of the P2X4 channel seems to be involved in the development of neuropathic pain by inducing the release of brain derived neurotrophic factor (BDNF) [47, 48]. In particular, this mechanism is believed to be responsible of the appearance of the tactile allodynia by inverting the ionic gradient of the GABAergic interneurons following the down-regulation of the KKC2 calcium transporter [47]. P2X4 receptor activation occurs earlier than that of $\mathrm{P} 2 \mathrm{X} 7$ channel due to the greater affinity of ATP to bind to P2X4 receptor. Indeed, P2X7 is involved in the maintenance of microglial activation. The P2X7 receptor appears to be a functionally unique ionotropic receptor among the P2X 
receptor family since its activation is able to stimulate the release of the pro-inflammatory cytokine interleukin-1 $\beta$ (IL-1 $\beta$ ) [49], as well as a variety of other pro-inflammatory cytokines. Recent studies have revealed that P2Y12R is also crucial in neuropathic pain induction and maintenance. It has been found that the expression of P2Y12R mRNA and protein are markedly enhanced in the spinal cord ipsilaterally to spinal nerve injury [50] or to sciatic nerve partial ligation [51]. The cellular location of this receptor in the spinal cord was highly restricted to microglia and recently has been proposed to be involved in the motility of microglial cell bodies and processes [52]. It is therefore possible that P2Y12R activity in microglia affects their ability to extend the branched processes toward neighbouring neurons of the pain matrix, which, in turn, may interfere with microglia-neuron communications. Recent data suggest that the metabotropic adenosine receptor A2A is also involved in the microglia process retraction occurring during microglia activation [53]. The up-regulation of Gs protein-coupled adenosine A2A receptor on activated microglia seems to occur concomitantly to down regulation of Giprotein coupled P2Y12 receptor [53].

\section{Supraspinal pathophysiology change mechanisms}

Descending pain modulatory system undergoes morpho-functional changes following PNS or CNS injury contributing to neuropathic pain development and maintenance [54-56]. The pain modulatory centers include brainstem areas such as periacqueductal gray (PAG), locus cœreuleus (LC) and rostral ventromedial-medulla (RVM). PAG is recognised as a major source of pain inhibitory control: its activation produces hypoalgesia by inhibiting nociceptive sensory processing within the dorsal horn of the spinal cord [57, 58]. PAG-induced analgesia is produced through the activation of RVM consisting of the raphe magnus and its adjacent reticular nuclei. Different pain responding cell populations are found in RVM: ON, OFF and neutral cells. These cells show different reactions to nociceptive stimuli such as excitation, inhibition or irresponsiveness, respectively $[59,60]$. Apart from their well-documented role in anti-nociception, PAG and RVM mediate also a descending facilitation [61, 62]. Indeed, a shift in the balance between RVM "pronociceptive" ON cells versus "antinociceptive" OFF cell activity has been found in neuropathic pain conditions. The ongoing firing of RVM ON cells was found significantly increased whereas the spontaneous activity of the OFF cells appeared decreased 7 days after neuropathic pain induction [60, 63]. A functional shift between ON and OFF cell activity such that ON cell activity predominates over that of the OFF may be responsible of the facilitatory influence of the RVM on spinal neurons leading to neuropathic hypersensitivity [64-66, 16, 67]. Moreover, a contribute of serotonergic neurons, considered a subset of neutral cells, in nociceptive modulation has been evidenced in abnormal pain states [68]. Thus, changes in RVM cell activity may be considered a sort of sensitization of RVM neurons during neuropathic pain $[69,70]$ as consequence of altered peripheral inputs associated with spinal processing [71]. Alternatively, RVM cell activity changes may reflect a different control exerted from the upstream PAG projections. Indeed, a complex morphofunctional reorganization has been observed within the PAG after neuropathic pain induction. A decrease in the potency of (R)-(+)-[2,3-dihydro-5-methyl-3-(4-morpholinylmethyl)pyrro- 
lo[1,2,3-de]-1,4-benzoxazin-6-yl]-1-naphthalenylmethanonemesylate (WIN 55,212-2), a cannabinoid receptor agonist, locally microinjected into the ventrolateral (VL) PAG, has been recently evidenced in neuropathic rats. Seven days after the CCI of the sciatic nerve WIN 55,212-2 produced antinociception and inhibited the activity of the ON cells while increased those one of the OFF cells (as centrally acting analgesic drugs are expected to do) at doses twofold higher than in control rats [67]. Moreover, the expression of cannabinoid type 1 (CB1) receptor, the CB1 receptor associated Goi3 and the cannabinoid receptor interacting 1a (CRIP 1a) proteins and the endocannabinoid synthesising enzyme NAPE-PLD proved to be decreased in CCI rats [67]. Thus a down regulation of the endocannabinoid system within the VL PAG, possibly due to endocannabinoid increase in neuropathic pain state [72], may lead to an enhancement in pain responses through an altered control of PAG-RVM circuitry on spinal nociceptive neurons. A hyperactivity of serotonergic neurons and an increase in endocannabinoids was also observed in CCI animals in dorsal raphe (DR), an area which lies just ventrally and shows similar morphological properties to the PAG [73]. DR phenotypic changes during neuropathic pain may have also relevance for the affective component of chronic pain. Another supraspinal circuitry being involved in to the emotional-affective aspects of pain is the basolateral amygdala (BLA)-medial prefrontal cortex ( $\mathrm{mPFC}$ ) pathway. Pyramidal neurons of $\mathrm{mPFC}$ respond to BLA electrical stimulation or hind-paw pressoceptive stimulation with an inhibitory [BLA $\rightarrow \mathrm{mPFC}(-)$ ] or excitatory [BLA $\rightarrow \mathrm{mPFC}(+)$ ] response [74]. These neurons show a phenotypic rearrangement in SNI-induced mono-neuropathy in the rat, suggesting that the $\mathrm{mPFC}$ may undergo profound reorganization in chronic pain conditions [75]. Neuropathic pain can shift the balance between excitatory and inhibitory responses in the BLA $\rightarrow \mathrm{mPFC}$ pathway, resulting in a net increase in the excitatory influence that the BLA exerts over the prelimbic/infralimbic (PL/IL) neuron population of the MPFC [76-80]. These functional changes appeared concomitantly with an increase in glutamate levels, as well as an up-regulation of fatty acid amide hydrolase (FAAH) enzyme and TRPV1 channels in the PL/IL cortex of SNI rats [75]. Overexpression of several caspases such as caspase-3 and 1, upregulation of glutamate AMPA receptors in microglia, IL-1 $\beta$ and IL-1 receptor-1, TRPV1 and vesicular glutamate transporter 1 (VGluT1) in glutamatergic neurons were also observed 7 days after SNI in mice. Of these alterations, only those in astrocytes persisted in SNI TPRV1(-/-) mice. SNI triggers both TRPV1-dependent and independent glutamate- and caspase-mediated cross-talk among IL-PL cortex neurons and glia, which either participates or counteracts pain processing. Alterations in endovanilloid system associated with peripheral nerve injury may suggest that therapies able to normalize endovanilloid transmission or blocking caspase activation may prove useful in ameliorating symptoms and central sequelae associated with neuropathic pain [80,75]. Within the VL PAG the expression of pronociceptive mediator targets such as the prostaglandin EP1 receptor, whose activation has pain facilitatory role, proved to be reduced 7 days after neuropathic pain induction by SNI. However, its blockade and stimulation was still able to inhibit/facilitate pain responses and the ON and OFF cell activity, as they did in control animals. The major expression of EP1 receptor was found on GABAergic neurons consistently with an EP1 receptor blockade-induced disinhibition of the antinociceptive descending pathway at VL PAG level and behavioural antinociception [16]. 


\section{Cannabinoids and peripheral neuropathy}

The discovery and characterization of cannabinoid receptors (CBRs) in the late eighties [81, 82] and the subsequent isolation of endogenous ligands, first of all the arachidonoylethanolamide (AEA) [83], established the existence of a proper endocannabinoid neuromodulatory system. Cannabinoids include the components of the cannabis plant (Cannabis sativa L.), the endogenous cannabinoids (endocannabinoids), and several synthetic cannabinoid ligands. The cannabinoid system is involved in several human physiological functions as testified by the fact that cannabis intake affects important aspects of behaviour such as short-term memory, panic reactions, motor coordination, food-intake and pain perception [84, 85]. More than 70 psychoactive compounds have been identified in cannabis, among which $\Delta^{9}$-tetrahydrocannabinol (THC) accounting for most of the psychological and physical effects. Cannabinoids exert their effects through the activation of two $G$ protein-coupled receptors identified as the cannabinoid CB1 and CB2. Their activation is associated with inhibition of adenylate cyclase and the stimulation of mitogen-activated protein kinase (MAPK). Moreover, CB1 receptor activation modulates calcium or potassium conductance properties linked to the reduction of neuronal excitability and neurotransmitter release [86]. CB1 receptor is wide expressed in the brain, including neuroanatomical regions subserving transmission and modulation of pain signals, such as the PAG, the RVM and the dorsal horn of the spinal cord [87, 88]. CB2 is found manly in the peripheral immune system. It is expressed on T and B cells, macrophages, natural killer and monocytes, however recent studies suggest its expression on neurons at dorsal root ganglia level and at central level within spinal cord, specifically on glia, microglia and neurons $[89,28]$. Pharmacological evidence also support the existence of non-CB1/CB2 receptormediated cannabinoid effects [90] and different investigations have been identified possible targets in the orphan G protein-coupled receptor GPR55 [91], transient receptor potential vanilloid type-1 (TRPV1) channel [92] or peroxisome proliferator-activated receptors (PPARs) [93]. The endocannabinoids such as AEA, arachidonoylglycerol (2-AG) and N-arachidonoyldopamine (NADA) are lipid compounds produced on demand by the cleavage of membrane phospholipid precursors, released from cells immediately after their production and degraded by specific enzymatic system. AEA is synthesized from enzymatic cleavage of $\mathrm{N}$-arachidonoyl phosphatidylethanolamine (NAPE) by a specific phospholipase D (NAPE-PLD). It shows higher affinity for CB (Ki [CB1 vs CB2] = 89 vs $371 \mathrm{nM}$ ) and can also activate ionotropic TRPV1 receptors as endovanilloids. Biological inactivation of anandamide occurs through a rapid uptake followed by intracellular hydrolysis mediated by FAAH.

2-AG, which is more abundant than anandamide in the brain binds to CB1 and CB2 with a lower affinity than anandamide, but behaves like a full agonist since it shows higher intrinsic activity [94]. 2-AG is synthesized by the enzyme diacylglycerol lipase (DGL- $\alpha$ ) in a $\mathrm{Ca}^{2+}-$ dependent pathway [95]. Other alternative mechanisms of 2-AG synthesis have also been proposed [96]. Biological inactivation occurs through uptake followed by hydrolysis mediated by the enzyme monoacylglycerol lipase (MGL). Other enzymes have been indicated for 2-AG metabolism, including cyclooxygenases (COXs), lipooxygenases (LOXs) and FAAH [97, 98]. The first evidence of the analgesic properties of cannabis was observed in 1899 by Dixon [99]. Crucial studies on cannabinoid-induced antinociception by Bicher and Mechoulam (1968) 
[100] and Kosersky [101] confirmed the ability of cannabinoids to inhibit acute and inflammatory and nerve injury-induced pain. Cannabinoids seem to be useful in alleviating neuropathic pain symptoms after prolonged treatments [102], unlike opioids, which show only limited effectiveness $[103,104]$. The activation of the CB receptors by synthetic agonists, or pharmacological elevation of endocannabinoid levels, suppresses hyperalgesia and allodynia in animal models of neuropathic pain. Local administration of exogenous AEA or 2-AG significant decreases the hyperalgesia in formalin test or in the PNL $[105,106]$. Systemic FAAH inhibitor (URB597, AA-5-HT, OL-135) administration or the inhibition of endocannabinoid uptake with AM404 produce antinociceptive effects in CCI [107] or PNL models [3] which are mainly CB1 receptor-mediated. It is also important to highlight that inhibitors of FAAH elevate levels of fatty-acid amides that do not bind to CB receptors (e.g. palmitoylethanolamine). Thus, the contribute of non-cannabinoid receptor mechanisms of action in the in vivo pharmacological effects of FAAH and MGL inhibitors must also be considered. Direct evidence for supraspinal sites of cannabinoid analgesic action was derived from the observation that administration of cannabinoids compounds straight into the brain induces antinociception. Martin et al. (1999) [108] demonstrated that WIN55,212-2 produced antinociception in the tailflick test when injected into different brain regions including subnuclei of the amygdala, thalamus, PAG and RVM.

In addition, as previously briefly described, WIN55,212-2 microinjection into the PAG suppressed the sciatic nerve constriction-induced allodynia and modulated RVM cells activity [67]. Similar effects have been shown by intra-PAG injection of a FAAH inhibitor URB597 which elevates endocannabinoid levels and reduces the thermal nociception via activation of CB1 and TRPV1 receptor mechanisms [109]. Moreover, Giordano et al. (2011) [80] have shown that acute intra-pre-limbic/infra-limbic cortex microinjection of $\mathrm{N}$-arachidonoyl-serotonin (AA-5-HT), a hybrid FAAH inhibitor and TPRV1 channel antagonist, transiently decreased the allodynia and modulates the changes occurring on cortex pyramidal neurons induced by SNI model.

In the complex scenario of neuropathic pain, which also involves non-neuronal pathways, such as microglial cell-induced synaptic plasticity, the endocannabinoid system may also represent target to exploite for modulating microglia-neuron communication. Several studies have focused on CB2 receptor activation in different neuropathic pain models [110, 28, 111, 112].

Such studies have highlighted the role of CB2 receptor in the modulation of immune response involved in the development of neuropathic pain. CB2 receptor activation exerts antiallodynic and antihyperalgesic effects by modulating microglia responses. In particular, CB2 receptor stimulation induced an analgesic effect in SNI mice associated with a reduction in the pro-inflammatory (IFN- $\gamma$ and IL-1 $\beta$ ) and an enhancement in anti-inflammatory (IL-10) mediators within the spinal cord [28]. Beside the analgesic effect, cannabis intake can impair cognitive and performance tasks, such as memory and learning [113]. Activation of central CB1 receptors lead to a combination of stimulatory and depressant effects [114]. Other effects including catalepsy, motor deficits and thermal imbalance have been observed after administration of centrally acting cannabinoids [115] These effects, mainly associated with activation of central CB1 receptors, deeply limit the clinical use of 
cannabinoids for the treatment of chronic pain states. The synthesis of CB2 receptorselective agonists which lack of the majority of central side effects and produce antinociceptive effects represent an interesting pharmacological tool [116].

Cannabinoids can counteract pain in both physiological and pathological conditions. CB1Rs and CB2Rs are both overexpressed during inflammation and neuropathic pain. In this context, selective activation of peripheral CB1 or CB2 receptor by cannabinoid agents which do not penetrate the blood brain barriers or the enhancement of the endocannabinoid levels can be a promising therapeutic approach that avoid the side effects associated with central CB1 receptor activation. Finally the isolation of non psychotropic compounds of Cannabis Sativa, such as cannabidiol or cannabichromene, which show antinociceptive properties in physiological [117] and pathological [118] pain conditions, could represent an alternative tool in pain management.

\section{Stem cell treatment for peripheral neuropathy}

Management of peripheral neuropathy in affected patients could be tailored to individual requirements, for instance the presence of other co-morbidities could influence the therapy. Damaged peripheral nerves demonstrate some potential to regenerate, however, complete functional recovery is infrequent. Novel approaches are required in the clinical management of peripheral nerve injuries since the current surgical techniques result in deficient sensory recovery [119].

Nowadays, neuropathy research is focusing on newer cellular and molecular approaches, such as stem cell therapy. Preclinical studies indicate that stem cell therapy represents the great promise for the future of molecular and regenerative medicine, including tissue regeneration. In peripheral neuropathy, stem cells could act in several ways: i) improving the intrinsic regenerative capacity of injured nerves; ii) inhibiting pathogenic immune responses both in the periphery and inside the central nervous system; iii) releasing neuroprotective and antiinflammatory molecules thus favouring tissue repair.

In the last years, it has been demonstrated that stem cells are neuroprotective in a variety of nervous system injury models [120]. Briefly, stem cells have been found in all multi-cellular organisms, they are able to divide and differentiate into diverse specialized cell types. In addition, stem cells self-renew themselves to produce more stem cells. Indeed, in principle, their extraordinary properties are the self-renewal (the ability to perform indefinite cell division cycles while maintaining the undifferentiated state) and the multipotency (the capacity to differentiate into specialized cell types). The availability of multiple stem cell types provides both the opportunity and a reasoned approach for treating several, otherwise untreatable, human diseases [121].

As neurodegenerative disease, also peripheral neuropathy could benefit by stem cell therapy. This cell- based treatment opportunity represents a non-surgical approaches to enhance nerve recovery and re-innervation processes [122, 123]. Indeed, stem cell implan- 
tation appears as a possible curative treatment having the stem cells the ability to incorporate into the site of a lesion, differentiate, and to improve locomotor recovery [124]. Stem cell beneficial effects are due to their properties, as self-renewal ability with the capacity to generate more identical stem cells; the capacity to give rise to more differentiated cells; the capacity to produce neuroprotective and anti-inflammatory molecules (paracrine regulatory functions) [121].

The ideal stem cell source for peripheral neuropathy repair should be easily accessible, involve non-invasive harvesting, be rapidly expandable in in vitro culture, be able to survive and integrate within the host nerve tissue [125]. Mesenchymal stem cells (MSCs) represent a promising therapeutic approach in nerve tissue engineering [126]. These cells are a population of progenitor cells of mesodermal origin found in the bone marrow of adults, giving rise to skeletal muscle cells, blood, adipose tissue, vascular and urogenital systems, and to connective tissues throughout the body [127]. This type of stem cells yields most prominent results in peripheral nerve re-generation. In addition, MSCs have great potential as therapeutic agents since they are easy to isolate and can be expanded from patients without serious ethical and technical problems [128]. MSC treatment into a polycaprolactone nerve guide was able to improve re-innervation and activity in mice undergone to nerve transection [129]. Interestingly, some transplanted stem cells assumed a Schwann-cell-like phenotype.

In a murine model of sciatic nerve crush injury, intravenous administration of adipose-derived MSC (ASC) significantly accelerated the functional recovery [126]. Mice showed significant improvement in fiber sprouting and the reduction of inflammatory infiltrates. The authors proposed that ASC-mediated positive effects were due to the production of in situ molecules, which, directly or indirectly through a cross-talk with local glia cells, could modulate the local environment with the down-regulation of inflammation and the promotion of axonal regeneration. Peripheral neuropathy is a dramatic symptom in Krabbe disease [130]. Hematopoietic stem cell (HSC) transplantation proved effective in slow the progression of this disease. HSCs were able to achieve improvement in peripheral nerve conduction abnormalities in Krabbe patients, suggesting remyelination of the nerves [131]. Diabetic neuropathy is the most common complication of diabetes, frequently leads to foot ulcers and may progress to limb amputations [132].

It has been proposed that autologous transplantation of bone marrow-derived mononuclear cells (BM-MNCs) could be a novel strategy for the treatment of painful diabetic neuropathy [133]. Indeed, transplantation of BM-MNCs is able to alleviate neuropathic pain in the early stage of streptozotocin-induced diabetic rats. The BM-MNC transplantation significantly ameliorated mechanical hyperalgesia and cold allodynia. Diabetic neuropathy is attracting most research strategies. Several clinical trials have been performed on the use of stem cells for the treatment of human peripheral diabetic neuropathy (www.clinicaltrials.gov). Induced pluripotent stem (iPS) cell technology has enormous potentials to advance medical therapy by personalizing regenerative medicine [134]. iPS cells offer great potentials as a future tool also for the treatment of peripheral neuropathy. Cell incorporation into conduit repair of peripheral nerves demonstrates experimental promise as a novel intervention. Tissue-engineered bio- 
absorbable nerve conduits coated with iPS cell-derived neurospheres were able to repair peripheral nerve gaps in mice [135].

Achieving peripheral nerve regeneration, axonal regeneration and re-myelination with stem cells is a challenging research goal. This process is very complex, with Wallerian degeneration being the most elementary reaction and Schwann cells playing an important role. An emerging solution to improve upon this intrinsic regenerative capacity is to supplement injured nerves with stem cells [136]. Stem cells effectiveness in the treatment of peripheral nerve injury may lie in their ability to differentiate into Schwann cells, secrete neurotrophic factors, and assist in myelin formation $[137,136]$. This strategy of introduction autologous stem cells directly into the site of a nerve injury represents a promising therapy. Skin-derived precursor cells (SKPs) were successfully transplanted in the sciatic nerve of Lewis rats bridged by a freeze-thawed nerve graft.

The cells were able to improve nerve re-generation, probably their effect was due to the ability to secrete bioactive neurotrophins [138]. Another stem cell type, the multipotent hair follicle stem cells, could provide a potential accessible, autologous source of stem cells for regeneration therapy of damaged nerves [139]. More recently, in an interesting study, Amoh et al. transplanted hair follicle stem cells around the impinged sciatic nerve of the mice. The cells differentiated into glia fibrillary acidic protein-positive Schwann cells, promoting the recovery of pre-existing axons. Authors reported that the regenerated sciatic nerve was functionally recovered [140]. These hair follicle stem cells could differentiate into several cell types, i.e. neurons, glia, keratinocytes, smooth muscle cells and melanocytes. They are nestin-positive cells and once implanted into the gap region of the sciatic or tibial nerve, are able to enhance the rate of nerve regeneration and the restoration of nerve function [141]. Wharton's jelly fishderived mesenchymal stem cells (WJMSCs) could be also a promising cell source for nerve tissue engineering. It has been demonstrated that these cells can be differentiated into Schwann-like cells and could be suitable Schwann-cell substitutes for nerve repair in clinical applications [142]. A recent strategy for peripheral nerve regeneration is based on the use of CD34(+) cells. Indeed, integration of CD34(+) cells in injured nerve significantly promotes nerve regeneration [143]. However, limited migration and short survival of CD34(+) cells could counteract this beneficial effect. One strategy could be the potentiation of CD34(+) cell recruitment triggered by stromal cell-derived factor-1 $\alpha$ (SDF-1 $\alpha$ ) [143]. This strategy based on the over-expression of SDF- $1 \alpha$ is providing interesting results in the peripheral neuropathy treatment. It has been proposed that the expression of SDF- $1 \alpha$ in the injured nerve exerts a trophic effect by recruiting progenitor cells that promote nerve regeneration. Intravenous administration of human amniotic fluid-derived mesenchymal stem cells facilitated neural regeneration in a sciatic nerve crush injury model, when recruited by expression of SDF- $1 \alpha$ in muscle and nerve after nerve crush injury [144]. As mesenchymal stem cells, amniotic fluidderived mesenchymal stem cells have the ability to secrete neurotrophic factors that are able to promote neuron survival. Their transplantation was able to regenerate the sciatic nerve after crush injury by secretion of neurotrophic factors [145]. Interestingly, the stem cell mediated effects could be enhanced by co-administration of several anti-inflammatory and anti- 
apoptotic factors, i.e. fermented soybean extracts or granulocyte-colony stimulating factor (GCSF) $[146,147]$.

In some cases, stem cell therapy does not provide optimal results. The multipotent capacity of stem cells to differentiate into many cell types has led to successful therapy, but concerns remain about the possible negative or harmful effects of the transplanted cultured cells [148]. Mahdi-Rogers et al. treated six patients with chronic acquired demyelinating neuropathy with autologous peripheral blood stem cell transplantation (PBSCT) [149]. These patients were refractory to other treatments; however, the authors reported serious adverse events and lack of sustained response. There have been reports of inflammatory peripheral neuropathy or polyneuropathy associated with chronic graft-versus-host disease (GVHD) [150], even if pathogenesis has not been fully cleared. Doi et al. report a case of immune-mediated neuropathy after allogenic hematopoietic stem cell transplantation for Philadelphia-chromosomepositive acute lymphoblastic leukemia [151].On the other hand, a case of peripheral neuropathy induction was reported after autologous blood stem cell transplantation for multiple myeloma [152]. Overall, these data indicate that before being suitable for clinical applications, stem cell biology needs to be investigated further and in greater detail [153].

\section{Conclusions}

Neuropathic pain involves a complex network of mechanisms involving peripheral and central nervous system. The peripheral nerve injury produces abnormal peripheral afferent inputs at the spinal dorsal horn which leads to development of central sensitization and plastic changes in supraspinal areas. The precise contribute of the different brain sites in neuropathic pain development and maintenance is still far to be established. In particular the contribute of the descending pain modulatory system including the PAG and the RVM is dual varying from inhibitory to facilitatory. By this subject strategies able to shift the balance between facilitatory versus inhibitory influences of the descending pathway may be useful to counteract neuropathic pain symptoms. Cannabinoids have been proved to stimulate the PAG-RVM inhibitory pain control and inhibit neuropathic pain-related allodynia and hyperalgesia.

Neurons are not the only cell type involved in plastic changes at the base of pain hypersensitivity and activated microglia actively contribute to pain facilitation through a tight interaction with neuron activity and the release of pain mediators. Novel strategies based on switching off the microglia activation represents a possible therapeutic intervention to alleviate neuropathic pain.

Human mesenchymal stem cell transplantation has shown to reduce astrocytic and microglial cell activation, mechanical allodynia and cellular and molecular pain mechanisms. The therapeutic potentiality of stem cell to alleviate neuropathic pain appears encouraging, however, its clinical application in peripheral neuropathy requires and deserves further investigations. 


\section{Author details}

Sabatino Maione, Enza Palazzo, Francesca Guida, Livio Luongo, Dario Siniscalco, Ida Marabese, Francesco Rossi and Vito de Novellis

Department of Experimental Medicine, Division of Pharmacology, Second University of Naples, Naples, Italy

\section{References}

[1] Wall, P. D, Devor, M, Inbal, R, Scadding, J. W, Schonfeld, D, Seltzer, Z, \& Tomkiewicz, M. M. Autotomy following peripheral nerve lesions: experimental anaesthesia dolorosa. Pain (1979). , 7(2), 103-11.

[2] Bennett, G. J, \& Xie, Y. K. A peripheral mononeuropathy in rat that produces disorders of pain sensation like those seen in man. Pain (1988). , 33(1), 87-107.

[3] Seltzer, Z, Dubner, R, \& Shir, Y. A novel behavioral model of neuropathic pain disorders produced in rats by partial sciatic nerve injury. Pain (1990). , 43(2), 205-18.

[4] Kim, S. H, \& Chung, J. M. (1992). An experimental model for peripheral neuropathy produced by segmental spinal nerve ligation in the rat. Pain , 50, 355-363.

[5] Decosterd, I, \& Woolf, C. J. Spared nerve injury: an animal model of persistent peripheral neuropathic pain. Pain (2000). , 87(2), 149-58.

[6] Courteix, C, Bardin, M, Chantelauze, C, Lavarenne, J, \& Eschalier, A. Study of thesensitivity of the diabetes-induced pain model in rats to a range of analgesics. Pain (1994). , 57(2), 153-60.

[7] Higuera, E. S, \& Luo, Z. D. A rat pain model of vincristine-induced neuropathy. Methods Mol Med. (2004). , 99, 91-8.

[8] Joseph, E. K, Chen, X, Khasar, S. G, \& Levine, J. D. Novel mechanism of enhanced nociception in a model of AIDS therapy-induced painful peripheral neuropathy in the rat. Pain (2004).

[9] Moalem, G, \& Tracey, D. J. Immune and inflammatory mechanisms in neuropathic pain. Brain Res Rev (2006). , 51(2), 240-64.

[10] Scholz, J, \& Woolf, C. J. The neuropathic pain triad: neurons, immune cells and glia. Nat Neurosci (2007). , 10, 1361-1368.

[11] Sommer, C, \& Kress, M. Recent findings on how proinflammatory cytokines cause pain: peripheral mechanisms in inflammatory and neuropathic hyperalgesia. Neurosci Lett. (2004). 
[12] Pezet, S, \& Mcmahon, S. B. Neurotrophins: mediators and modulators of pain. Annu Rev Neurosci. (2006). , 29, 507-38.

[13] Hudson, L. J, Bevan, S, Wotherspoon, G, Gentry, C, Fox, A, \& Winter, J. VR1 protein expression increases in undamaged DRG neurons after partial nerve injury. Eur J Neurosci (2001). , 13(11), 2105-14.

[14] Levine, J. D, \& Alessandri-haber, N. TRP channels: targets for the relief of pain. Biochim Biophys Acta (2007). , 1772(8), 989-1003.

[15] Palazzo, E, Luongo, L, De Novellis, V, Berrino, L, Rossi, F, \& Maione, S. Moving towards supraspinal TRPV1 receptors for chronic pain relief. Mol Pain (2010).

[16] Palazzo, E, Guida, F, Gatta, L, Luongo, L, Boccella, S, Bellini, G, Marabese, I, De Novellis, V, Rossi, F, \& Maione, S. EP1 receptor within the ventrolateral periaqueductal grey controls thermonociception and rostral ventromedial medulla cell activity in healthy and neuropathic rat. Mol Pain (2011).

[17] Woolf, C. J, \& Mannion, R. J. Neuropathic pain: Aetiology, symptoms, mechanisms, and management. Lancet (1999). , 353(9168), 1959-64.

[18] Hong, S, Morrow, T. J, Paulson, P. E, Isom, L. L, \& Wiley, J. W. Early painful diabetic neuropathy is associated with differential changes in tetrodotoxin-sensitive and-resistant sodium channels in dorsal root ganglion neurons in the rat. J Biol Chem (2004). , 279(28), 29341-50.

[19] Hong, S, \& Wiley, J. W. Early painful diabetic neuropathy is associated with differential changes in the expression and function of vanilloid receptor 1. J Biol Chem (2005). , 280(1), 618-27.

[20] Luo, Z. D, Chaplan, S. R, Higuera, E. S, Sorkin, L. S, Stauderman, K. A, Williams, M. E, \& Yaksh, T. L. Upregulation of dorsal root ganglion (alpha)2(delta) calcium channel subunit and its correlation with allodynia in spinal nerve-injured rats. J Neurosci (2001). , 21(6), 1868-75.

[21] Matthews, E. A, \& Dickenson, A. H. Effects of spinally delivered N- and P-type voltage-dependent calcium channel antagonists on dorsal horn neuronal responses in a rat model of neuropathy. Pain (2001).

[22] Scholz, J. Woolf CJ: The neuropathic pain triad: neurons, immune cells and glia. Nat Neurosci (2007).

[23] Garden, G. A, \& Moller, T. Microglia biology in health and disease. J Neuroimmune Pharmacol (2006). , 1, 127-137.

[24] Trapp, B. D, Wujek, J. R, Criste, G. A, et al. Evidence for synaptic stripping by cortical microglia. Glia (2007). , 55, 360-368.

[25] Coyle, D. E. Partial peripheral nerve injury leads to activation of astroglia and microglia which parallels the development of allodynic behavior. Glia (1998). , 23(1), 75-83. 
[26] Jin, S. X, Zhuang, Z. Y, Woolf, C. J, \& Ji, R. R. p38 mitogen-activated protein kinase is activated after a spinal nerve ligation in spinal cord microglia and dorsal root ganglion neurons and contributes to the generation of neuropathic pain. J Neurosci (2003). , 23(10), 4017-22.

[27] Ledeboer, A, Sloane, E. M, Milligan, E. D, et al. Minocycline attenuates mechanical allodynia and proinflammatory cytokine expression in rat models of pain facilitation. Pain (2005).

[28] Luongo, L, Palazzo, E, Tambaro, S, et al. 1-(2',4'-dichlorophenyl)-6- methyl-N-cyclohexylamine-1,4-dihydroindeno[1,2-c]pyrazole-3- carboxamide, a novel CB2 agonist, alleviates neuropathic pain through functional microglial changes in mice. Neurobiol Dis (2010). , 37, 177-85.

[29] Olechowski, C. J, Truong, J. J, \& Kerr, B. J. Neuropathic pain behaviours in a chronicrelapsing model of experimental autoimmune encephalomyelitis (EAE). Pain (2009).

[30] Luongo, L, Sajic, M, Grist, J, Clark, A. K, Maione, S, \& Malcangio, M. Spinal changes associated with mechanical hypersensitivity in a model of Guillain-Barré syndrome. Neurosci Lett (2008). , 437(2), 98-102.

[31] Stella, N. Endocannabinoid signaling in microglial cells. Neuropharmacology (2009). Suppl , 1, 244-53.

[32] Medzhitov, R. Origin and physiological roles of inflammation. Nature (2008). , 454(7203), 428-35.

[33] Romero-sandoval, A. Nutile-McMenemy N, DeLeo JA. Spinal microglial and perivascular cell cannabinoid receptor type 2 activation reduces behavioral hypersensitivity without tolerance after peripheral nerve injury. Anesthesiology (2008). , 108(4), 722-734.

[34] Milligan, E. D, \& Watkins, L. R. Pathological and protective roles of glia in chronic pain. Nat Rev Neurosci (2009). , 10(1), 23-36.

[35] Abbadie, C, Bhangoo, S, De Koninck, Y, Malcangio, M, Melik- Parsadaniantz, S, \& White, F. A. Chemokines and pain mechanisms. Brain Res Rev (2009). , 60(1), 125-34.

[36] Lever, I. J, Bradbury, E. J, Cunningham, J. R, et al. Brain-derived neurotrophic factor is released in the dorsal horn by distinctive patterns of afferent fiber stimulation. J Neurosci (2001). , 21, 4469-4477.

[37] Svensson, C. I, Hua, X. Y, Protter, A. A, Powell, H. C, Yaksh, T. L, \& Spinal, p. MAP kinase is necessary for NMDA-induced spinal PGE(2) release and thermal hyperalgesia. Neuroreport (2003a). , 14, 1153-1157.

[38] Taylor, D. L, Diemel, L. T, \& Pocock, J. M. Activation of microglial group III metabotropic glutamate receptors protects neurons against microglial neurotoxicity. J Neurosci (2003). , 23(6), 2150-60. 
[39] Biber, K, Laurie, D. J, Berthele, A, et al. Expression and signaling of group I metabotropic glutamate receptors in astrocytes and microglia. J Neurochem (1999). , 72(4), 1671-80.

[40] Bazan, J. F, Bacon, K. B, Hardiman, G, et al. A new class of membrane- bound chemokine with a CX3C motif. Nature (1997). , 385, 640-644.

[41] Lindia, J. A, Mcgowan, E, Jochnowitz, N, \& Abbadie, C. Induction of CX3CL1 expression in astrocytes and CX3CR1 in microglia in the spinal cord of a rat model of neuropathic pain. J Pain (2005). , 6, 434-438.

[42] Clark, A. K, Yip, P. K, Grist, J, et al. Inhibition of spinal microglial cathepsin S for the reversal of neuropathic pain. Proc Natl Acad Sci USA (2007). , 104, 10655-10660.

[43] Zhuang, ZY, Kawasaki, Y, Tan, PH, \& Wen, . . Role of the CX3CR1/p38 MAPK pathway in spinal microglia for the development of neuropathic pain following nerve injury-induced cleavage of fractalkine. Brain Behav Immun 2007; 21: 642- 651

[44] Thacker, M. A, Clark, A. K, Bishop, T, et al. CCL2 is a key mediator of microglia activation in neuropathic pain states. Eur J Pain (2009). , 13, 263-272.

[45] Abbadie, C, Lindia, J. A, Cumiskey, A. M, et al. Impaired neuropathic pain responses in mice lacking the chemokine receptor CCR2. Proc Natl Acad Sci USA (2003). , 100, 7947-7952.

[46] Inoue, K, Tsuda, M, \& Tozaki-saitoh, H. Modification of neuropathic pain sensation through microglial ATP receptors. Purinergic Signal (2007). , 3, 311-316.

[47] Coull, J. A, Beggs, S, Boudreau, D, et al. BDNF from microglia causes the shift in neuronal anion gradient underlying neuropathic pain. Nature (2005). , 438, 1017-1021.

[48] Ulmann, L, Hatcher, J. P, Hughes, J. P, et al. Up-regulation of receptors in spinal microglia after peripheral nerve injury mediates BDNF release and neuropathic pain. J Neurosci (2008). , 2 X4.

[49] Clark, A. K, Wodarski, R, Guida, F, Sasso, O, \& Malcangio, M. Cathepsin S release from primary cultured microglia is regulated by the receptor. Glia (2010). , 2 X7.

[50] Tozaki-saitoh, H, Tsuda, M, Miyata, H, Ueda, K, Kohsaka, S, \& Inoue, K. P. Y12 receptors in spinal microglia are required for neuropathic pain after peripheral nerve injury. J Neurosci (2008). , 28(19), 4949-56.

[51] Kobayashi, K, Yamanaka, H, Fukuoka, T, Dai, Y, Obata, K, \& Noguchi, K. P. Y12 receptor upregulation in activated microglia is a gateway of signaling and neuropathic pain. J Neurosci (2008). , 38.

[52] Haynes, S. E, Hollopeter, G, Yang, G, et al. The 2 Y12 receptor regulates microglial activation by extracellular nucleotides. Nat Neurosci (2006). 
[53] Orr, A. G, Orr, A. L, Li, X. J, Gross, R. E, Traynelis, S. F, \& Adenosine, A. A) receptor mediates microglial process retraction. Nat Neurosci (2009). , 12(7), 872-8.

[54] Pertovaara, A. Plasticity in descending pain modulatory systems. Prog Brain Res (2000). , 129, 231-42.

[55] Porreca, F, Ossipov, M. H, \& Gebhart, G. F. Chronic pain and medullary descending facilitation. Trends Neurosci. (2002). , 25(6), 319-25.

[56] Ossipov, M. H, \& Porreca, F. Chapter 14 Descending excitatory systems. Handb Clin Neurol. (2006). , 81, 193-210.

[57] Reynolds, D. V. Surgery in the rat during electrical analgesia induced by focal brain stimulation. Science (1969). Apr 25; 164(3878), 444-5.

[58] Jones, S. L, \& Gebhart, G. F. Inhibition of spinal nociceptive transmission from the midbrain, pons and medulla in the rat: activation of descending inhibition by morphine, glutamate and electrical stimulation. Brain Res (1988).

[59] Fields, H. L, Bry, J, Hentall, I, \& Zorman, G. The activity of neurons in the rostral medulla of the rat during withdrawal from noxious heat. J Neurosci. (1983).

[60] Fields, H. L, Basbaum, A. I, \& Heinricher, M. M. (2006). Central nervous system mechanisms of pain modulation. In Mcmahon, SB and Kolzenburg M (Eds), Wall and Melzack's textbook of pain, $5^{\text {th }}$ edn. Elsevier Location, China, , 125-142.

[61] Gebhart, G. F. Descending modulation of pain. Neurosci Biobehav Rev. (2004). Jan; 27(8), 729-37.

[62] Vanegas, H, \& Schaible, H. G. Descending control of persistent pain: inhibitory or facilitatory? Brain Res Brain Res Rev. (2004). , 46(3), 295-309.

[63] Gonçalves, L, Almeida, A, \& Pertovaara, A. Pronociceptive changes in response properties of rostroventromedial medullary neurons in a rat model of peripheral neuropathy. Eur J Neurosci (2007). , 26(8), 2188-95.

[64] Kovelowski, C. J, Ossipov, M. H, Sun, H, Lai, J, Malan, T. P, \& Porreca, F. Supraspinal cholecystokinin may drive tonic descending facilitation mechanisms to maintain neuropathic pain in the rat. Pain (2000). , 87(3), 265-73.

[65] Porreca, F, Burgess, S. E, Gardell, L. R, \& Vanderah, T. W. Malan TP Jr, Ossipov MH, Lappi DA, Lai J. Inhibition of neuropathic pain by selective ablation of brainstem medullary cells expressing the mu-opioid receptor. J Neurosci. (2001). , 21(14), 5281-8.

[66] Carlson, J. D, Maire, J. J, Martenson, M. E, \& Heinricher, M. M. Sensitization of painmodulating neurons in the rostral ventromedial medulla after peripheral nerve injury. J Neurosci (2007). , 27(48), 13222-31.

[67] Palazzo, E, Luongo, L, Bellini, G, Guida, F, Marabese, I, Boccella, S, Rossi, F, Maione, $\mathrm{S}, \&$ De Novellis, V. Changes in cannabinoid receptor subtype 1 activity and interaction with metabotropic glutamate subtype 5 receptors in the periaqueductal gray-ros- 
tral ventromedial medulla pathway in a rodent neuropathic pain model. CNS Neurol Disord Drug Targets. (2012). , 2012(11), 148-61.

[68] Suzuki, R, Rygh, L. J, \& Dickenson, A. H. Bad news from the brain: descending 5-HT pathways that control spinal pain processing. Trends Pharmacol. Sci. (2004). , 25, 613-617.

[69] Millecamps, M, Centeno, M. V, Berra, H. H, Rudick, C. N, Lavarello, S, \& Tkatch, T. Apkarian AV. D-cycloserine reduces neuropathic pain behavior through limbic NMDA-mediated circuitry. Pain (2007).

[70] Tracey, I, \& Mantyh, P. W. The cerebral signature for pain perception and its modulation. Neuron. (2007). , 55(3), 377-91.

[71] Campbell, J. N, \& Meyer, R. A. Mechanisms of neuropathic pain. Neuron (2006). , 52(1), 77-92.

[72] Petrosino, S, Palazzo, E, De Novellis, V, Bisogno, T, Rossi, F, \& Maione, S. Di Marzo $\mathrm{V}$. Changes in spinal and supraspinal endocannabinoid levels in neuropathic rats. Neuropharmacology (2007). , 52(2), 415-22.

[73] Palazzo, E, De Novellis, V, Petrosino, S, Marabese, I, Vita, D, \& Giordano, C. Di Marzo V, Mangoni GS, Rossi F, Maione S. Neuropathic pain and the endocannabinoid system in the dorsal raphe: pharmacological treatment and interactions with the serotonergic system. Eur J Neurosci. (2006). , 24(7), 2011-20.

[74] Floresco, S. B, \& Tse, M. T. Dopaminergic regulation of inhibitory and excitatory transmission in the basolateral amygdala-prefrontal cortical pathway. J Neurosci. (2007). Feb 21; 27(8), 2045-57.

[75] De Novellis, V, Vita, D, Gatta, L, Luongo, L, Bellini, G, De Chiaro, M, Marabese, I, Siniscalco, D, Boccella, S, \& Piscitelli, F. Di Marzo V, Palazzo E, Rossi F, Maione S. The blockade of the transient receptor potential vanilloid type 1 and fatty acid amide hydrolase decreases symptoms and central sequelae in the medial prefrontal cortex of neuropathic rats. Mol Pain (2011). , 17, 7-7.

[76] Fu, Y, \& Neugebauer, V. Differential mechanisms of CRF1 and CRF2 receptor functions in the amygdala in pain-related synaptic facilitation and behavior. J Neurosci. 20089;, 28(15), 3861-76.

[77] Neugebauer, V, Galhardo, V, Maione, S, \& Mackey, S. C. Forebrain pain mechanisms. Brain Res Rev (2009). , 60(1), 226-42.

[78] Ji, G, \& Neugebauer, V. Hemispheric lateralization of pain processing by amygdala neurons. J Neurophysiol (2009). , 102(4), 2253-64.

[79] Metz, A. E, Yau, H. J, Centeno, M. V, Apkarian, A. V, \& Martina, M. Morphological and functional reorganization of rat medial prefrontal cortex in neuropathic pain. Proc Natl Acad Sci U S A (2009). , 106(7), 2423-8. 
[80] Giordano, C, Cristino, L, Luongo, L, Siniscalco, D, Petrosino, S, Piscitelli, F, Marabese, I, Gatta, L, Rossi, F, Imperatore, R, Palazzo, E, \& De Novellis, V. Di Marzo V, Maione S. Cereb Cortex (2011). in press

[81] Matsuda, L. A, Lolait, S. J, Brownstein, M. J, Young, A. C, \& Bonner, T. I. Structure of a cannabinoid receptor and functional expression of the cloned cDNA. Nature (1990). , 346, 561-564.

[82] Herkenham, M, Lynn, A. B, Johnson, M. R, Melvin, L. S, De Costa, B. R, \& Rice, K. C. Characterization and localization of cannabinoid receptors inrat brain: a quantitative in vitro autoradiographic study J Neurosci(1991). , 1, 563-583.

[83] Devane, W. A, Hanus, L, Breuer, A, et al. Isolation and structure of a brain constituent that binds to the cannabinoid receptor Science (1992). , 258, 1946-1949.

[84] Fride, E, Bregman, T, \& Kirkham, T. C. Endocannabinoids and food intake: newborn suckling and appetite regulation in adulthood. Exp Biol Med (2005). Review., 230(4), 225-34.

[85] Guindon, J, \& Hohmann, A. G. The endocannabinoid system and pain.CNS Neurol Disord Drug Targets. (2009). Review., 8(6), 403-21.

[86] Howlett, A. C. Cannabinoid receptor signaling. Handb. Exp. Pharmacol (2005). , 168, 53-79.

[87] Bushlin, I, Rozenfeld, R, \& Devi, L. A. Cannabinoid-opioid interactions during neuropathic pain and analgesia. Curr Opin Pharmacol. (2010). , 10(1), 80-6.

[88] Miller, L. K, \& Devi, L. A. The highs and lows of cannabinoid receptor expression in disease: mechanisms and their therapeutic implications. Pharmacol Rev. (2011). , 63(3), 461-70.

[89] Van Sickle, M. D, Duncan, M, Kingsley, P. J, Mouihate, A, Urbani, P, Mackie, K, Stella, N, Makriyannis, A, Piomelli, D, Davison, J. S, \& Marnett, L. J. Di Marzo V, Pittman QJ, Patel KD, Sharkey KA. Identification and functional characterization of brainstem cannabinoid CB2 receptors Science (2005). , 310, 329-332.

[90] Staton PC, Hatcher JP, Walker DJ, Morrison AD, Shapland EM, Hughes JP, Chong E, Mander PK, Green PJ, Billinton A, Fulleylove M, Lancaster HC, Smith JC, Bailey LT, Wise A, Brown AJ

[91] Sharir, H. and Abood, M.E. Pharmacological characterization of GPR55, a putative cannabinoid receptor Pharmacol. Ther 2010;126(3):301-313

[92] Zygmunt, P. M, Petersson, J, Andersson, D. A, Chuang, H, \& Sorgard, M. Di Marzo, V., Julius, D., and Hogestatt, E.D. Vanilloid receptors on sensory nerves mediate the vasodilator action of anandamide Nature (1999). , 400(6743), 452-457.

[93] Sullivan, O. S.E. Cannabinoids go nuclear: evidence for activation of peroxisome proliferator-activated receptors Br. J. Pharmacol. (2007). , 152(5), 576-582. 
[94] Stella, N, Schweitzer, P, \& Piomelli, D. A second endogenous cannabinoid that modulates long-term potentiation Nature (1997). , 388, 773-778.

[95] Beltramo, M, \& Piomelli, D. Carrier-mediated transport and enzymatic hydrolysis of the endogenous cannabinoid 2-arachidonylglycerol Neuropharmacology (2000). , 11, 1231-1235.

[96] Di Marzo VTargeting the endocannabinoid system: to enhance or reduce? Nat Rev Drug Discov (2008). , 7, 438-455.

[97] Kozak, K. R, Rowlinson, S. W, \& Marnett, L. J. Oxygenation of the endocannabinoid, 2 arachidonylglycerol, to glyceryl prostaglandins by cyclooxygenase-2 J Biol Chem (2000). , 275, 33744-33749.

[98] Blankman, J. L, Simon, G. M, \& Cravatt, B. F. A comprehensive profile of brain enzymes that hydrolyze the endocannabinoid 2- arachidonoylglycerol Chem Biol (2007). , 14, 1347-1356.

[99] Dixon, W. E. The pharmacology of cannabis indica Br Med J (1899). , 2, 1354-7.

[100] Bicher, H. I, \& Mechoulam, R. Pharmacological effects of two active constituents of marihuana Arch Int Pharmacodyn Ther 196 ;, 172, 24-31.

[101] Kosersky, D. S, Dewey, W. L, \& Harris, L. S. Antipyretic, analgesic and anti-infl ammatory effects of delta 9-tetrahydrocannabinol in the rat Eur J Pharmacol (1973). , 24, $1-7$.

[102] Costa, B, Colleoni, M, Conti, S, Trovato, A. E, Bianchi, M, Sotgiu, M. L, \& Giagnoni, G. Repeated treatment with the synthetic cannabinoid WIN 55,212-2 reduces both hyperalgesia and production of pronociceptive mediators in a rat model of neuropathic pain Br J Pharmacol (2004). , 141(1), 4-8.

[103] Ossipov, M. H, Lopez, Y, Nichols, M. L, Bian, D, \& Porreca, F. The loss of antinociceptive efficacy of spinal morphine in rats with nerve ligation injury is prevented by reducing spinal afferent drive.Neurosci Lett (1995). , 199(2), 87-90.

[104] Rashid, M. H, Inoue, M, Toda, K, \& Ueda, H. Loss of peripheral morphine analgesia contributes to the reduced effectiveness of systemic morphine in neuropathic pain J Pharmacol Exp Ther. (2004). , 309(1), 380-7.

[105] Guindon, J, \& Beaulieu, P. Antihyperalgesic effects of local injections of anandamide, ibuprofen, rofecoxib and their combinations in a model of neuropathic pain Neuropharmacology (2006). , 50, 814-823.

[106] Helyes, Z, Németh, J, Thán, M, Bölcskei, K, Pintér, E, \& Szolcsányi, J. Inhibitory effect of anandamide on resiniferatoxin-induced sensory neuropeptide release in vivo and neuropathic hyperalgesia in the rat Life Sci (2003). , 73, 2345-2353.

[107] Costa, B, Siniscalco, D, Trovato, A. E, Comelli, F, Sotgiu, M. L, Colleoni, M, Maione, S, Rossi, F, \& Giagnoni, G. AM404, an inhibitor of anandamide uptake, prevents pain 
behaviour and modulates cytokine and apoptotic pathways in a rat model of neuropathic pain Br J Pharmacol (2006). , 148, 1022-1032.

[108] Martin, W. J, Coffin, P. O, Attias, E, Balinsky, M, Tsou, K, \& Walker, J. M. Anatomical basis for cannabinoid-induced antinociception as revealed by intracerebral microinjections Brain Res. (1999).

[109] Maione, S, Bisogno, T, De Novellis, V, Palazzo, E, Cristino, L, Valenti, M, Petrosino, S, Guglielmotti, V, \& Rossi, F. Di Marzo V. Elevation of endocannabinoid levels in the ventrolateral periaqueductal grey through inhibition of fatty acid amide hydrolase affects descending nociceptive pathways via both CB1 and TRPV1 receptors. J Pharmacol Exp Ther (2006). , 316, 969-982.

[110] Racz, I, Nadal, X, Alferink, J, Baños, J. E, Rehnelt, J, Martín, M, Pintado, B, Gutierrezadan, A, Sanguino, E, Manzanares, J, Zimmer, A, \& Maldonado, R. Crucial role of $\mathrm{CB}(2)$ cannabinoid receptor in the regulation of central immune responses during neuropathic pain. J Neurosci (2008a). , 28(46), 12125-35.

[111] Racz, I, Nadal, X, Alferink, J, Baños, J. E, Rehnelt, J, Martín, M, Pintado, B, Gutierrezadan, A, Sanguino, E, Bellora, N, Manzanares, J, \& Zimmer, A. Maldonado R Interferon-gamma is a critical modulator of $\mathrm{CB}(2)$ cannabinoid receptor signaling during neuropathic pain.J Neurosci. (2008B). , 28(46), 12136-45.

[112] Anand, P, Whiteside, G, Fowler, C. J, \& Hohmann, A. G. Targeting CB2 receptors and the endocannabinoid system for the treatment of pain Brain Res Rev (2009). , 60(1), 255-66.

[113] Hampson, R. E, \& Deadwyler, S. A. Cannabinoids, hippocampal function and memory. Life Sci (1999). Review

[114] Pertwee, R. G. The central neuropharmacology of psychotropic cannabinoids. Pharmacol Ther. (1988). Review

[115] Maccarrone, M, \& Wenger, T. Effects of cannabinoids on hypothalamic and reproductive function. Handb Exp Pharmacol (2005).

[116] Ibrahim, M. M, Lai, J, Vanderah, T. W, Makriyannis, A, \& Porreca, F. CB2 cannabinoid receptor agonists: pain relief without psychoactive effects? Curr Opin Pharmacol (2003). Review., 3(1), 62-7.

[117] Maione, S, Piscitelli, F, Gatta, L, Vita, D, De Petrocellis, L, Palazzo, E, \& De Novellis, V. Di Marzo V. Non-psychoactive cannabinoids modulate the descending pathway of antinociception in anaesthetized rats through several mechanisms of action $\mathrm{Br} \mathrm{J}$ Pharmacol (2011). , 162(3), 584-96.

[118] Costa, B, Trovato, A. E, Comelli, F, Giagnoni, G, \& Colleoni, M. The non-psychoactive cannabis constituent cannabidiol is an orally effective therapeutic agent in rat chronic inflammatory and neuropathic pain Eur J Pharmacol (2007). 
[119] Reid, A. J, Sun, M, Wiberg, M, Downes, S, Terenghi, G, \& Kingham, P. J. Nerve repair with adipose-derived stem cells protects dorsal root ganglia neurons from apoptosis. Neuroscience. (2011). , 199, 515-522.

[120] Siniscalco, D, Rossi, F, \& Maione, S. Stem cell therapy for neuropathic pain treatment. J Stem Cells and Regenerative Medicine (2008). vol III (1).

[121] Siniscalco, D, Bradstreet, J. J, \& Antonucci, N. Cell therapies for Autism Spectrum Disorders. Autism Spectrum Disorders: New Research. (2012). Edited by : Nova Science Publishers, Hauppauge, NY.

[122] Dadon-nachum, M, Sadan, O, Srugo, I, Melamed, E, \& Offen, D. Differentiated mesenchymal stem cells for sciatic nerve injury. Stem Cell Rev (2011a). , 7(3), 664-71.

[123] Martínez de Albornoz PDelgado PJ, Forriol F, Maffulli N. Non-surgical therapies for peripheral nerve injury. Br Med Bull (2011). , 100, 73-100.

[124] Dadon-nachum, M, Melamed, E, \& Offen, D. Stem cells treatment for sciatic nerve injury. Expert Opin Biol Ther (2011b). , 11(12), 1591-1597.

[125] Azizi, S. A, Stokes, D, \& Augelli, B. J. DiGirolamo C, Prockop DJ. Engraftment and migration of human bone marrow stromal cells implanted in the brains of albino rats- similarities to astrocyte grafts. Proc. Natl. Acad. Sci USA(1998). , 95, 3908-3913.

[126] Marconi, S, Castiglione, G, Turano, E, Bissolotti, G, Angiari, S, Farinazzo, A, Constantin, G, Bedogni, G, Bedogni, A, \& Bonetti, B. Human adipose-derived mesenchymal stem cells systemically injected promote peripheral nerve regeneration in the mouse model of sciatic crush. Tissue Eng Part A. (2012).

[127] Siniscalco, D. Transplantation of human mesenchymal stem cells in the study of neuropathic pain. Methods Mol Biol. (2010). , 617, 337-345.

[128] Dezawa, M. Future views and challenges to the peripheral nerve regeneration by cell based therapy. Rinsho Shinkeigaku (2005). , 45(11), 877-879.

[129] Frattini, F. Pereira Lopes FR, Almeida FM, Rodrigues RF, Boldrini LC, Tomaz MA, Baptista AF, Melo PA, Martinez AM. Mesenchymal Stem Cells in a Polycaprolactone Conduit Promote Sciatic Nerve Regeneration and Sensory Neuron Survival After Nerve Injury. Tissue Eng Part A. (2012). in press.

[130] Malandrini, A, Eramo, D, Palmeri, C, Gaudiano, S, Gambelli, C, Sicurelli, S, Berti, F, Formichi, G, Kuqo, P, Dotti, A, \& Federico, M. T. A. Peripheral neuropathy in lateonset Krabbe disease: report of three cases. Neurol Sci. (2012). in press.

[131] Siddiqi, Z. A, Sanders, D. B, \& Massey, J. M. Peripheral neuropathy in Krabbe disease: effect of hematopoietic stem cell transplantation. Neurology. (2006). , 67(2), 268-272. 
[132] Kim, H, Kim, J. J, \& Yoon, Y. S. Emerging therapy for diabetic neuropathy: cell therapy targeting vessels and nerves. Endocr Metab Immune Disord Drug Targets. (2012). , 12(2), 168-178.

[133] Naruse, K, Sato, J, Funakubo, M, Hata, M, Nakamura, N, Kobayashi, Y, Kamiya, H, Shibata, T, Kondo, M, Himeno, T, Matsubara, T, Oiso, Y, \& Nakamura, J. Transplantation of bone marrow-derived mononuclear cells improves mechanical hyperalgesia, cold allodynia and nerve function in diabetic neuropathy. PLoS One (2011). e27458.

[134] Ebben, J. D, Zorniak, M, Clark, P. A, \& Kuo, J. S. Introduction to induced pluripotent stem cells: advancing the potential for personalized medicine. World Neurosurg (2011).

[135] Uemura, T, Takamatsu, K, Ikeda, M, Okada, M, Kazuki, K, Ikada, Y, \& Nakamura, H. Transplantation of induced pluripotent stem cell-derived neurospheres for peripheral nerve repair. Biochem Biophys Res Commun (2012). , 419(1), 130-135.

[136] Walsh, S. K, Kumar, R, Grochmal, J. K, Kemp, S. W, Forden, J, \& Midha, R. Fate of stem cell transplants in peripheral nerves. Stem Cell Res. (2012). , 8(2), 226-238.

[137] Ren, Z, Wang, Y, Peng, J, Zhao, Q, \& Lu, S. Role of stem cells in the regeneration and repair of peripheral nerves. Rev Neurosci. (2012). , 23(2), 135-143.

[138] Walsh, S, Biernaskie, J, Kemp, S. W, \& Midha, R. Supplementation of acellular nerve grafts with skin derived precursor cells promotes peripheral nerve regeneration. Neuroscience (2009). , 164(3), 1097-1107.

[139] Amoh, Y, \& Hoffman, R. M. Isolation and culture of hair follicle pluripotent stem (hfPS) cells and their use for nerve and spinal cord regeneration. Methods Mol Biol. (2010). , 585, 401-420.

[140] Amoh, Y, Aki, R, Hamada, Y, Niiyama, S, Eshima, K, Kawahara, K, Sato, Y, Tani, Y, Hoffman, R. M, \& Katsuoka, K. Nestin-positive hair follicle pluripotent stem cells can promote regeneration of impinged peripheral nerve injury. J Dermatol. (2012). , 39(1), 33-38.

[141] Hoffman, R. M. The potential of nestin-expressing hair follicle stem cells in regenerative medicine. Expert Opin Biol Ther. (2007). , 7(3), 289-291.

[142] Peng, J, Wang, Y, Zhang, L, Zhao, B, Zhao, Z, Chen, J, Guo, Q, Liu, S, Sui, X, Xu, W, $\&$ Lu, S. Human umbilical cord Wharton's jelly-derived mesenchymal stem cells differentiate into a Schwann-cell phenotype and promote neurite outgrowth in vitro. Brain Res Bull. (2011). , 84(3), 235-243.

[143] Sheu, M. L, Cheng, F. C, Su, H. L, Chen, Y. J, Chen, C. J, Chiang, C. M, Chiu, W. T, Sheehan, J, \& Pan, H. C. Recruitment by SDF-1 $\alpha$ of CD34-positive cells involved in sciatic nerve regeneration. J Neurosurg (2012). , 116(2), 432-444. 
[144] Yang, D. Y, Sheu, M. L, Su, H. L, Cheng, F. C, Chen, Y. J, Chen, C. J, Chiu, W. T, Yiin, J. J, Sheehan, J, \& Pan, H. C. Dual regeneration of muscle and nerve by intravenous administration of human amniotic fluid-derived mesenchymal stem cells regulated by stromal cell-derived factor- $1 \alpha$ in a sciatic nerve injury model. J Neurosurg. (2012). , 116(6), 1357-1367.

[145] Pan, H. C, Cheng, F. C, Chen, C. J, Lai, S. Z, Lee, C. W, Yang, D. Y, Chang, M. H, \& Ho, S. P. Post-injury regeneration in rat sciatic nerve facilitated by neurotrophic factors secreted by amniotic fluid mesenchymal stem cells. J Clin Neurosci. (2007). , 14(11), 1089-1098.

[146] Pan, H. C, Yang, D. Y, Ho, S. P, Sheu, M. L, Chen, C. J, Hwang, S. M, Chang, M. H, \& Cheng, F. C. Escalated regeneration in sciatic nerve crush injury by the combined therapy of human amniotic fluid mesenchymal stem cells and fermented soybean extracts, Natto. J Biomed Sci. (2009). a..

[147] Pan, H. C, Chen, C. J, Cheng, F. C, Ho, S. P, Liu, M. J, Hwang, S. M, Chang, M. H, \& Wang, Y. C. Combination of G-CSF administration and human amniotic fluid mesenchymal stem cell transplantation promotes peripheral nerve regeneration. Neurochem Res. (2009). b., 34(3), 518-527.

[148] Mohseny AB Hogendoorn PCConcise review: Mesenchymal tumors when stem cells go mad. Stem Cells. (2011). , 29, 397-403.

[149] Mahdi-rogers, M, Kazmi, M, Ferner, R, Hughes, R. A, Renaud, S, Steck, A. J, Fuhr, P, Halter, J, Gratwohl, A, \& Tyndall, A. Autologous peripheral blood stem cell transplantation for chronic acquired demyelinating neuropathy. J Peripher Nerv Syst (2009). , 14(2), 118-124.

[150] Amato, A. A, Barohn, R. J, Sahenk, Z, Tutschka, P. J, \& Mendell, J. R. Polyneuropathy complicating bone marrow and solid organ transplantation. Neurology (1993). , 43, 1513-1518.

[151] Doi, Y, Sugahara, H, Yamamoto, K, Uji-ie, H, Kakimoto, T, \& Sakoda, H. Immunemediated peripheral neuropathy occurring simultaneously with recurrent graft-versus-host disease after allogenic hematopoietic stem cell transplantation. Leuk Res. (2012). e, 63-65.

[152] Boiron, J. M, Ellie, E, Vital, A, Marit, G, Rème, T, Vital, C, Broustet, A, \& Reiffers, J. Peripheral neuropathy after autologous blood stem cell transplantation for multiple myeloma. Leukemia (1994). , 8(2), 322-326.

[153] Siniscalco, D, Giordano, A, \& Galderisi, U. Novel insights in basic and applied stem cell therapy. J Cell Physiol (2012). , 227(5), 2283-2286. 
